\title{
Nama keratopathy
}

\author{
JEFFREY FREEDMAN
}

Department of Ophthalmology, University of the Witwatersrand, and Baragwanath Hospital, Johannesburg, South Africa

A study of ocular diseases among the Nama peoples of South West Africa was undertaken by the Department of Ophthalmology of the Witwatersrand during July, 197I. The Nama people are a pure-bred race having their origins in South Africa. They are not a Negroid people but like the Bushmen belong to the Khoisan group.

\section{Material}

The people surveyed lived in the Keetmanshoop area of South West Africa (Freedman, 1973). A census taken in the area estimates the number of Nama to be $\mathrm{I}, 200$; the survey covered 680 persons of all ages (see Table I: Freedman, 1973).

\section{Method}

A full ophthalmological examination, including slit-lamp examination and applanation tensioß readings, was made. A summary of the eye diseases found is reported in the previous communication (Freedman, 1973). The present paper deals with the most striking ocular pathology seen, namele gelatinous dystrophy of the cornea, also called band-shaped nodular dystrophy.

\section{Clinical findings}

The degeneration was found equally in males and females (Table), the highest incidence occurring in the older age groups. 50 per cent. of those over the age of 55 showed some degree of degeneration. The youngest patient with the disease was 35 years old.

Table Incidence by age and sex of oil droplet dystrophy

\begin{tabular}{|c|c|c|c|c|c|c|c|c|c|c|c|}
\hline \multirow{2}{*}{\multicolumn{2}{|c|}{$\frac{\text { Age group }}{\text { Sex }}$}} & \multicolumn{2}{|c|}{$35^{-44}$} & \multicolumn{2}{|c|}{$45^{-55}$} & \multicolumn{2}{|c|}{$55^{-64}$} & \multicolumn{2}{|c|}{$65-74$} & \multicolumn{2}{|c|}{$75^{-84}$} \\
\hline & & $M$ & $F$ & $M$ & $F$ & $M$ & $F$ & $M$ & $F$ & $M$ & $F$ \\
\hline \multicolumn{2}{|c|}{ Total no. seen } & $5 I$ & 33 & 35 & $3^{8}$ & 37 & 30 & 25 & I 9 & 7 & 7 \\
\hline \multirow{2}{*}{$\begin{array}{l}\text { Patients } \\
\text { with } \\
\text { dystrophy }\end{array}$} & $\mathcal{N} o$ & 6 & I & 5 & I 2 & 20 & 12 & I 3 & 10 & 5 & 3 \\
\hline & Per cent. & $\overline{12}$ & - & $\overline{14}$ & $\overline{33}$ & $\overline{54}$ & $\overline{45}$ & $\overline{5^{\circ}}$ & $\overline{5^{0}}$ & $\overline{80}$ & $\overline{50}$ \\
\hline
\end{tabular}

The area of cornea involved is the horizontal interpalpebral strip, with a tendency towards the lower half of the cornea. Although the majority of cases showed bilateral involvement, some cases of unilateral involvement were seen. An interesting feature was that, in bilateral cases, the left eye was always more severely involved and in uniocular cases the left eye was the one predominantly involved. 


\section{Stages of the disease}

Like Labrador keratopathy (Freedman, 1965), the disease can be divided into three grades.

(I) In the earliest type, only the medial and lateral parts of the interpalpebral area were involved. The characteristic finding was the presence of small oil droplets in Bowman's membrane, seen only by slit-lamp and retro-illumination, which began in an arcus senilis and seemed initially to be present only in the arcus. Arcus senilis, as such, appeared in 66 people over the age of 35 years, an incidence of 24 per cent.

At this early stage, vision, although not tested, did not seem to be impaired and a clear view of the fundus could be obtained. The corneal stroma was not involved.

(2) The second stage was characterized by a diffuse spread across the cornea in the interpalpebral region. Seen macroscopically, the involved parts presented as a hazy area of cornea interfering with a clear view of the fundus (Fig. I). The "oil droplets" varied in size; some were large, and the beginning of extension into the deeper parts of the corneal epithelium was seen. The cornea was non-vascularized and not painful. The only subjective complaint was diminished visual acuity.

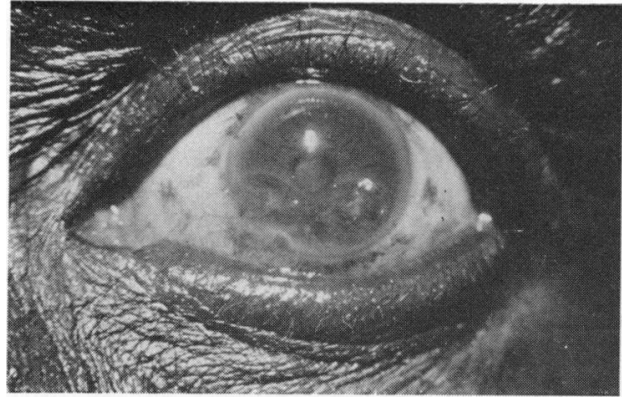

FIG. I Small oil droplets spread diffusely over lower half of cornea

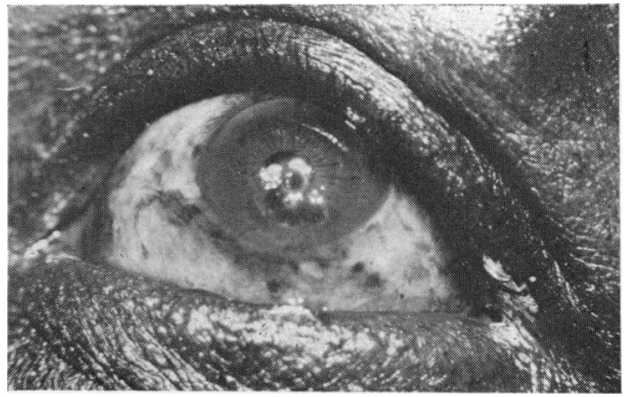

FIG. 2 Large "nodular" oil droplets involving lower half of cornea spreading to cover the pupil

(3) In the third stage the whole of the interpalpebral area of the cornea was involved with extension into the lower half of the cornea. In no case had extension of the dystrophy into the upper half of the cornea occurred. This stage was also characterized by extension into the superficial parts of the stroma and large nodular "oil droplets" were seen (Fig. 2).

\section{Discussion}

Gelatinous dystrophy, as found in the Nama people, would appear to be similar to Labrador keratopathy described by Freedman (1965). The condition differs in both areas from band-shaped keratopathy in that no calcification is found. As was found in the Labrador series most of the cases in South West Africa fell into Grade I, only two examples of Grade 3 being seen.

In considering aetiology, genetic causes may play a part, as a similar corneal dystrophy is also found in the Bantu-speaking Negroes of Southern Africa, but no cases have been reported in the Caucasians of Southern Africa.

Unlike the Labrador condition, the Nama keratopathy seemed to be influenced by poor nutrition, as the most severe cases were seen in elderly persons who were found to be undernourished. 
ASSOCIATED OCULAR DISEASES

This condition, like Labrador keratopathy, did not commonly occur with other eye diseases, and is therefore unlikely to be a secondary phenomenon. In five cases seen in the survey, pseudo-capsular exfoliation without glaucoma, but with gelatinous dystrophy, was seen. This was not observed at all in the Labrador series. The association of pseudocapsular exfoliation and gelatinous dystrophy would appear to be unique to the southern part of Africa. Gelatinous dystrophy was first described in the South African Negro by Etzine and Kaufmann ( 1964 ) and it is common anomg the Bantu-speaking Negroes who attend clinics at the St. John Eye Hospital in Johannesburg. A report of the prevalence of gelatinous dystrophy in these people will follow. The Bantu-speaking Negroes of South Africa also show pseudocapsular exfoliation both with and without glaucoma (Luntz, I972). As in the Labrador study, pterygium was not found to be present in cases of droplet dystrophy although it does occur among the Nama people.

CLIMATIC FACTORS

The climate of South West Africa would appear to be relevant to the occurrence of the disease. The temperature in Keetmanshoop area varies from a mean of $80^{\circ} \mathrm{F}$. in summer to $55^{\circ} \mathrm{F}$. in winter. The average annual duration of sunshine expressed as a percentage of possible sunshine is 80 per cent. The mean annual rainfall is 5 ", and the rain occurs sporadically in showers of short duration which do not greatly interrupt the sunshine. Because of high temperatures and abundant sunshine, evaporation is intense over all South Africa and in particularly in South West Africa, so that the climate in the Keetmanshoop area is hot, dry, and arid, whereas in Labrador it is cold, dry, and arid.

Bietti, Guerra, and Ferraris de Gaspare (1955), who described nodular corneal dystoph in East Africa, also noted the dryness of the area and surmised that evaporation of tearso probably helped to cause the corneal condition. Thus, low relative humidity is a commonf factor in the climates of South West Africa, Labrador, and East Africa. Wind-blown dust is prevalent in South West Africa as Keetmanshoop is situated in the Namib Desert area.

However, factors other than climate seem also to contribute to the causation of the dystrophy, as it also occurs in the Bantu-speaking Negroes of South Africa living in a temperate climate, although no cases have been reported in Caucasians. A striking feature reported by Freedman (1965), Bietti and others (1955), and Etzine and Kaufmann (1964) is the predominance in males, but in the Nama people females appeared to be equally affected.

Corneal dystrophy of a similar nature is therefore found in four different parts of the world, three of which have a common denominator of aridity, abundant sunshine, and wind-blown particles of dust or ice.

PREVENTION

Because the condition is more prevalent in the elderly, it would seem that the causative factors have to be present for a long time, and this may be significant if prevention is to be attempted as it would have to be started at an early age. Moisturizing drops such as liquifilm should perhaps be used by those with a racial predisposition to the corneal dystrophy who are exposed to the elements for lengthy periods, but this is only a surmise and a long-term study would be necessary to assess the efficacy of such a measure.

\section{Summary}

Gelatinous corneal dystrophy, also called "oil droplet dystrophy" is described in the Nama people of South West Africa. The condition is similar to Labrador keratopathy 
and is characterized by degeneration of the superficial cornea in the interpalpebral area.

Climatic conditions would appear to be a significant causative factor.

I am grateful to Prof. M. H. Luntz, Head of the Department of Ophthalmology at the University of the Witwatersrand, for the opportunity of making this survey.

My thanks are also due to the Department of Orthopaedic Surgery at this University for help and cooperation during the survey.

Financial assistance was received from the University of the Witwatersrand and the South African Medical Research Council.

\section{References}

BIETti, G. B., GUerRa, P., and FerRaris De GASPARE, P. F. (I955) Bull. Soc. franf. Ophtal., 68, IOI ETZine, s., and KaUfmann, J. E. c. (1964) Amer. 7. Ophthal., 57, 76o

FreEdMan, A. (1965) Arch. Ophthal. (Chicago), 74, 198

FREEDMAN, J. (I973) Brit. 7. Ophthal., 57, 681 (Fig. I)

LUNTZ, M. H. (I972) "Glaucoma and Ocular Hypertension," pp. 243-245. 